\title{
Effects of reinforcing arrangement of kenaf fibres into unsaturated polyester for improved properties
}

\section{R. Islam ${ }^{1 *}$ and M. D. H. Beg ${ }^{2}$}

${ }^{1}$ Section of Chemical Engineering, Malaysian Institute of Chemical and Bioengineering Technology, University of Kuala Lumpur, Alor Gajah-78000, Melaka, Malaysia.

${ }^{2}$ Faculty of Chemical and Natural Resources Engineering, Universiti Malaysia Pahang, Lebuhraya Tun Razak, Gambang 26300, Kuantan, Malaysia.

*Email: muhammad.remanul@unikl.edu.my

\begin{abstract}
In this current study, the mechanical, structural and morphological properties of kenaf fibre based polyester composites based on reinforcing arrangement were investigated. Fibres were placed in layers into the resin to enhance reinforcement. A hand lay-up technique was used to prepare the sandwich composite. Composites were characterized by tensile, flexural and impact testing. The structural properties as well as crystalline behaviour were observed by X-ray diffraction analysis. Additionally, the surface of the fractured samples was also examined using scanning electron microscopy to understand the interaction behaviour between the fibres and matrix. Results of the analyses revealed that single layered kenaf mat enhanced the tensile strength by $80 \%$, whereas the double layered improved by $156 \%$, in the presence of a fixed amount of curing agent. The thermal properties of the composites based on double layered kenaf mat were also found to improve compared to the others. The double layered composites can be used as high temperature-sustained roofing materials to replace traditional products.
\end{abstract}

Keywords: Polyesters; composites; kenaf fibres; mechanical properties; thermal properties.

\section{INTRODUCTION}

Natural fibres (NFs) possesses a number of benefits which add values to polymer composites in terms of strength, structural flexibility, light weight, renewability and cost reduction [1-8]. In addition, environmental sustainability and reduced demand of polymer are also considered as significant impacts of using them with polymer matrices [9-11]. There are drawbacks of using NFs, which are also found in the literature as reported by different researchers. For example, NFs are hydrophilic, which is different than natural polymer as they are more hydrophobic in nature $[12,13]$. This negative characteristic enhances moisture absorption by composites, and makes them incompatible with polymer matrix, resulting in poor interfacial adhesion and weakened formulated composites. In addition, it limits the use of composites for high performance and outdoor applications. The properties of composites depend on various parameters like matrix and fibre strength, fibre aspect ratio, interfacial adhesion between fibres and matrices, etc. An effective reinforcement can produce good composite performance. The reinforcement of NFs inside polymer matrices can be done efficiently by different techniques, such as physical and chemical treatments of fibre, usage of coupling agent and processing technique of composites formulation [14-16]. Few common and efficient processing techniques 
include extrusion, injection and compression moulding. For liquid resin, melt mixing and compression moulding are effective. Hot or cold pressing at high pressure and required temperature have also been found as effective reinforcing techniques.

The dispersion and placement of fibres inside polymer matrix is important. The fibre loading can be made up to 40 to $50 \%$. The properties of the composites depend on the volume of the fibre, aspect ratio, size, orientation into the polymer, processing techniques, types and quality of the fibres, and the polymer matrix used [1, 17-19]. The alignment of fibres according to axial or bi-axial arrangement has been found influential in varying the strength of the composites. Therefore, the current study deals with fibre dispersion inside the matrices for improved performance of kenaf fibre based polyester composites. Important NFs for composite preparation are sisal, kenaf, jute, coir, oil palm empty fruit bunch, etc. Among the fibres, kenaf is long fibre and suitable to be incorporated into polymer matrix for reinforcement purposes. Kenaf fibres have been used for composite fabrication with different thermoplastic and thermosetting polymers like polypropylene, polyesters, polyethylene, etc [12, 20-23]. Studies have reported that fabrication methods use 3 to $5 \mathrm{~mm}$ chopped fibres [9]. The variations in properties are also claimed as a function of fibre loading and aspect ratio [24]. Polyester from among the thermosetting resins is used for composite preparation [24, 25]. They are important in hand lay-up technique for easy fabrication of the composites. The aim of this study was to determine the effects of reinforcing arrangement of kenaf mats as layers into a polymer matrix, polyesters. The reinforcing arrangement has a significant contribution on mechanical properties, which has not been reported for the case of kenaf mat and polyester composites.

\section{MATERIALS AND METHODS}

\section{Materials}

Green kenaf fibres were collected from Kuala Rompin, Pahang, Malaysia. The fibres were dried in sunlight for four days at $32^{\circ} \mathrm{C}$. The net structure was prepared by placing ten long $(25 \mathrm{~cm})$ fibres horizontally and ten vertically one-after-another like a net structure. The polymer matrix chosen was commercially available unsaturated polyester (UP) resin, whereas methyl ethyl ketone peroxide (MEKP) and cobalt naphthenate were used as accelerator and catalyst, respectively, for the curing process of the resin.

\section{Composite Fabrication}

The amount of liquid resin required to soak all of the fibers completely was considered to be as much as resin. It was estimated that $100 \mathrm{ml}$ of resin is sufficient for single layered and randomly oriented fibres, whereas, $150 \mathrm{ml}$ is adequate for double layered. The amount of MEKP used for $100 \mathrm{ml}$ of resin was $5 \mathrm{ml}$ and for $150 \mathrm{ml}$ was $7 \mathrm{ml}$. The amount of cobalt naphthenate used for all samples was $0.5 \mathrm{mg}$. The fabricated composites were of two types: single layered and double layered. The process flow including the formulation of the composites and the formulated samples are illustrated in Figure 1. For comparison, 2-5 $\mathrm{mm}$ fibres were mixed with the liquid resins. The sample prepared without fibre is called UP, single layered fibre based UP composite (SUPC), double layered fibre based UP composite (DUPC) and randomly oriented fibre based UP composite (RUPC). 

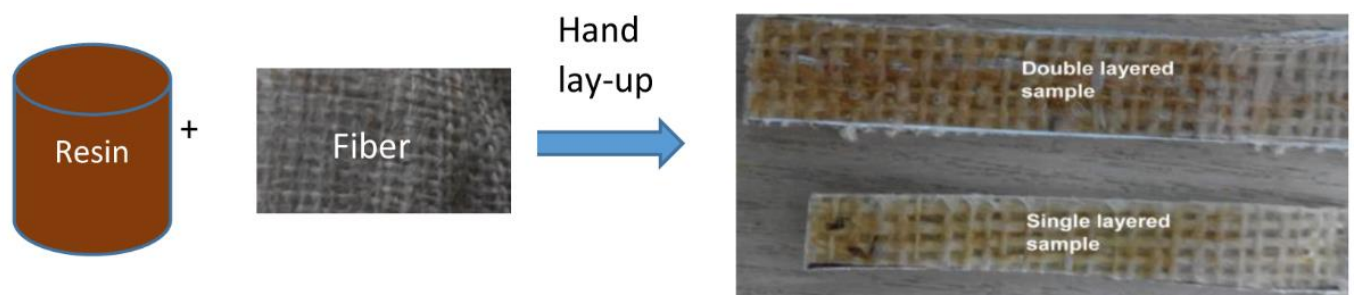

Figure 1. Samples showing double layered and single layered fibre replacement inside the polymer matrix.

\section{Tensile Properties}

The tensile test was carried out using Universal Testing Machine AG-1 (Shidmadzu, Japan), following the method described in ASTM D $638-01$. The cross-head speed was fixed at $10 \mathrm{~mm} / \mathrm{min}$ and gauge length was maintained at $65 \mathrm{~mm}$. The experimental set-up for this testing is presented in Figure 2. Five specimens were tested, and the average value was taken for data analysis.

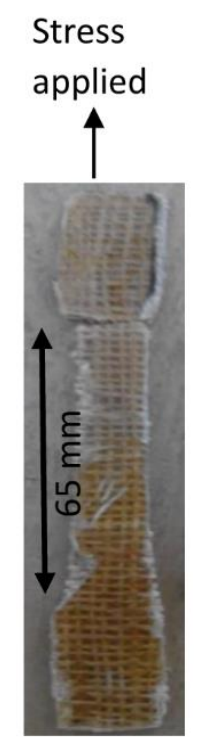

Figure 2. Tensile testing of the sample.

\section{Flexural Properties}

The flexural test was conducted according to ASTM D790-97 method by using a universal testing machine (model- SHIMADZU, AG-1) with static load cell of $1 \mathrm{kN}$. The support was set at $20 \mathrm{~mm}$, and the cross-head speed was fixed at $10 \mathrm{~mm} / \mathrm{min}$. Five specimens were tested, and the average value was taken for data analysis.

\section{Charpy Impact Test}

The charpy impact tests were performed using impact pendulum tester (modelZWICK/ROELL) at $90^{\circ}$ swing angle with a hammer of load $1 \mathrm{~J}$. The charpy impact tests were carried out according to ASTM D256 standard with a rectangular specimen test bar of fixed dimension $(55 \times 3.3 \times 10 \mathrm{~mm})$. The Davenport notch cutting apparatus were used to notch the specimen and the notch depth was fixed at $2 \mathrm{~mm}$ with an angle of $45^{\circ}$. Five specimens were tested, and the average value was taken for data analysis. 


\section{X-ray Diffraction Analysis}

The crystalline property of the polymer matrix and the composites were measured by Xray diffraction (XRD) analysis. For this purpose, A Rigaku Mini Flex II, Japan, was used with tube current and operating voltage $15 \mathrm{~mA}$ and $30 \mathrm{kV}$, respectively. The samples were scanned step-wise from $5^{\circ}$ to $40^{\circ}$ with a scattering angle $(2 \theta)$ by using $\mathrm{Cu} \mathrm{K}_{\alpha}$ radiation of wavelength $\lambda 1.541 \AA$.

\section{SEM}

A scanning electron microscope (SEM) (model-ZESIS) was used to observe the surface images of the fractured samples. The samples were dried in an oven at $60^{\circ} \mathrm{C}$ before the observation. Air dried samples were fixed to a metal-base specimen holder using doublesided sticky carbon tape, and then coated with gold using a vacuum sputter-coater to make them conductive prior to SEM observation.

\section{Thermal Analysis}

Thermogravimetric measurements were carried out using a thermogravimetric analyser (TGA) of model: TA instrument, TGA Q500. Each sample was weighed nearly $5 \mathrm{mg}$ and heated at a temperature range of $40-600^{\circ} \mathrm{C}$ with a heating rate of $20^{\circ} \mathrm{C} / \mathrm{min}$. TGA analyses were conducted in a platinum crucible under nitrogen atmosphere at a flow rate of 40 $\mathrm{ml} / \mathrm{min}$ to ensure inert atmosphere.

\section{RESULTS AND DISCUSSION}

\section{Tensile Properties}

The tensile strength (TS) and tensile modulus (TM) of UP and composites based on randomly-oriented short fibres as well as kenaf mat of different number of layers are illustrated in Figure 3. From the results, the tensile strength of UP was found to be 5.1 $\mathrm{MPa}$, which improved by up to 7.0 MPa through the incorporation of randomly oriented short kenaf fibres. This increase could be due to the load transfer and interfacial adhesion between the fibres and matrix [12]. On the other hand, the incorporation of single layered kenaf fibres mat enhanced the TS $(9.2 \mathrm{MPa})$ by $80 \%$, which further improved by the incorporation of double layered kenaf fibre mat. DUPC showed a TS of $13.1 \mathrm{MPa}$, which was an increment by $156 \%$ from UP and $42 \%$ from SUPC. The improvement for SUPC compared to RUPC was probably due to equal load transfer by the structured kenaf mat, whereas the highest TS was observed by DUPC as a result of double layered mat, which contributes equal maximum load transfer due to structured fibres arrangement [26].

The same trend was obtained for TM. The TM of UP, RUPC, SUPC, DUPC was found to be 90, 120, 322 and $464 \mathrm{MPa}$, respectively. Significant enhancement in tensile strength and modulus was obtained with increasing number of fibre layers. The fibres mainly play an interesting role in enhancing the stiffness of the composites by supporting the applied load. Therefore, by increasing the fibre layer, the degree of obstruction increases, which consequently increases the stiffness of the composites [27].

\section{Flexural Properties}

The flexural strength (FS) and flexural modulus (FM) of the composites are illustrated in Figure 4. The FS of UP, RUPC, SUPC and DUPC was found to be 11.5, 15.7, 19.2 and 23.1 MPa, whereas the FM was found to be 235, 320, 422 and $564 \mathrm{MPa}$, respectively. FS improved due to the incorporation of randomly-oriented fibres. Normally hard PU are brittle, but due to fibres inclusion, the applied load was shared and the stress transfer was 
possibly carried out through the fibres, which ultimately improved the stiffness of the composites, and as a result improved the bending strength [13]. However, the single layered kenaf mat enhanced FS from 11.5 to $19.2 \mathrm{MPa}$, which was $3.5 \mathrm{MPa}$ higher than RUPC. Finally, the maximum FS (23.1 MPa) was observed with double layered mat. The same trend of results was observed for FM. The maximum FM was noted for DUPC as $564 \mathrm{MPa}$, which was $140 \%$ higher than PU. The improvement was thought to be due to higher interfacial adhesion built due to the special arrangement of the fibre mat [1].

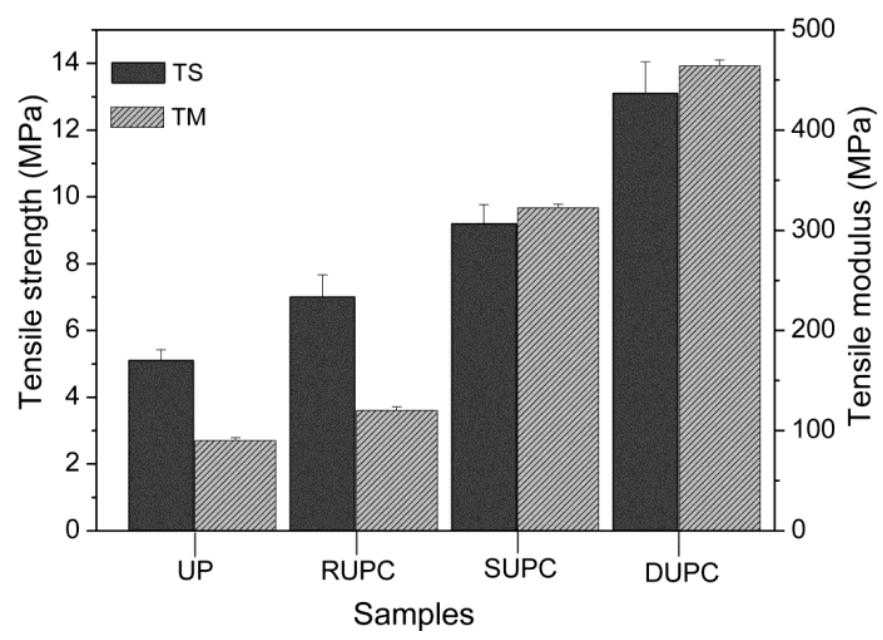

Figure 3. Tensile strength (MPa) and tensile modulus (MPa) of the composites.

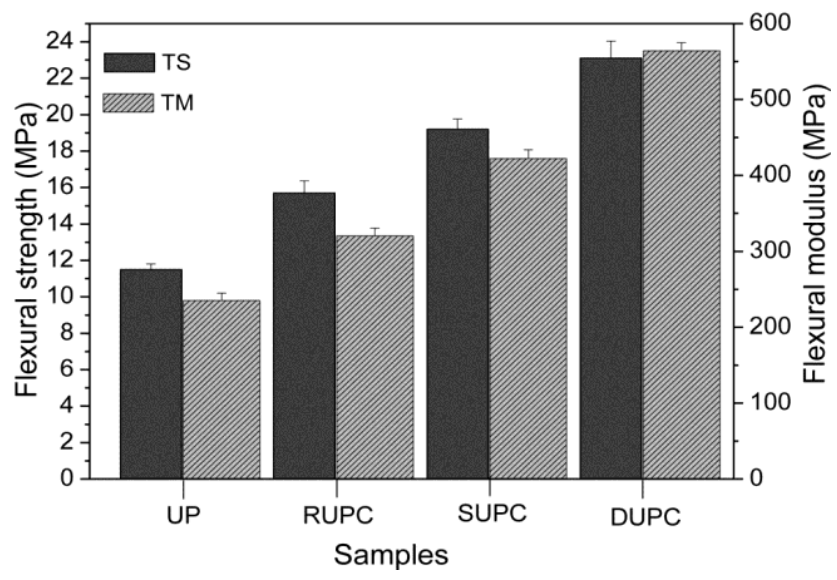

Figure 4. Flexural strength and flexural modulus of the composites.

\section{Charpy Impact Properties}

The impact strength (IS) of UP and composites are tabulated in Table 1. The IS of UP was found to be $3.82 \mathrm{~kJ} / \mathrm{m}^{2}$, whereas RPEC showed a higher value of $4.56 \mathrm{~kJ} / \mathrm{m}^{2}$. On the other hand, the incorporation of single layered kenaf mat enhanced the value to 10.83 $\mathrm{kJ} / \mathrm{m}^{2}$, which was found to decrease with further layer (second layer) to $9.73 \mathrm{~kJ} / \mathrm{m}^{2}$. The value decreased due to the probability of fibre agglomeration, which resulted in stress concentration region which requires less energy for crack propagation [28]. In addition, it was also reported that the impact strength decreased with fibre loading due to weak interfacial bonding between fibre and matrix, which causes micro crack to occur at the point of impact. Similar observation was documented elsewhere [29, 30]. It was based on the phenomenon of as fibres volume increases, the wettability decreases as an outcome 
of lack of interfacial adhesion. Therefore, the formation of solid interface bond requires less energy absorption to be cracked.

Table 1. Impact strength of UP and different composites.

\begin{tabular}{ll}
\hline Samples & $\mathrm{IS}\left(\mathrm{kJ} / \mathrm{m}^{2}\right)$ \\
\hline UP & 3.82 \\
RUPC & 4.56 \\
SUPC & 10.83 \\
DUPC & 9.73 \\
\hline
\end{tabular}

\section{Structural Properties}

The XRD diffractograms of different samples are presented in Figure 5. It can be seen that all samples including UP, RUPC, SUPC and DUPC show similar trend of curve, except for changing intensities. The curve intensity of fibre loaded UP was slightly high due to higher amount of crystallinity [31]. The fibre acted as a nucleating agent which were thought to be the reason behind this statement. Table 2 shows the crystallinity of the samples that was calculated based on the graphs generated by XRD diffractrograms. RUPC showed higher intensity compared to UP. The crystallinity was found to be $44 \%$ for the case of UP, whereas RUPC showed a crystallinity of 53\%. Improved interfacial adhesion between the fibre and matrix is a possible reason behind this observation. Further, the crystallinity was found to improve for the case of SUPC due to single layered kenaf mat (58\%), which was found to be the lowest (50\%) among the composites for the case of DUPC. The increment of crystallinity was probably due to the presence of crystalline cellulose fibre and their special arrangement into the matrix [12].

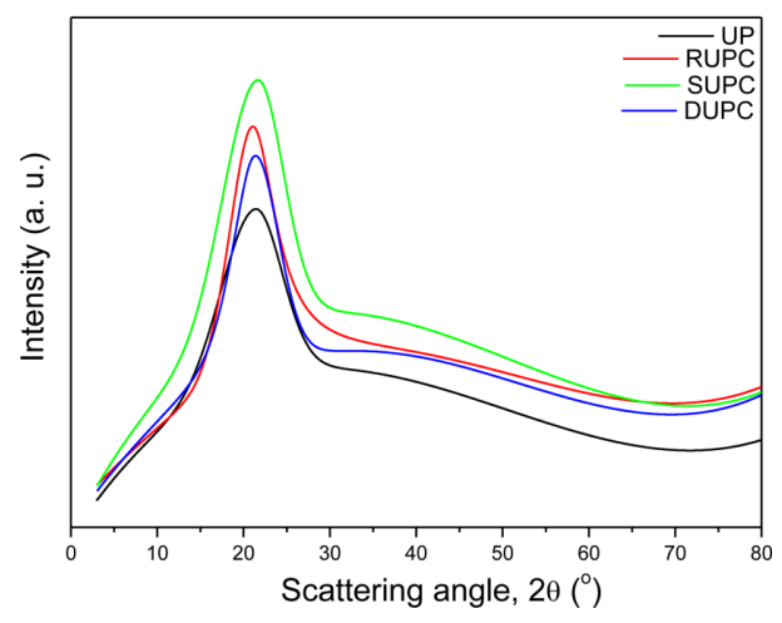

Figure 5. XRD patterns of different samples.

\section{Surface Morphology}

The surface morphology of the tensile fractured samples is represented in Figure 6. Figure 6(a) shows the surface of the UP sample. From the image, the fracture was visible on the surface due to its brittleness. After randomly loading kenaf fibres, the surface (Figure 6(b)) was found to be rigid without any visible fracture. Therefore, it can be stated that the brittleness of the sample was reduced due to the incorporation of the fibres. Likewise, the surface of SUPC and DUPC was found to be similar, where no fracture was found. From another point of view, pulled out fibre due to stress was found to be maximum with 
DUPC, as a large number of fibres were visible. In comparison, the surface of RUPC and SUPC showed lesser amount of pulled out fibre which is as a consequence of better interfacial adhesion between fibres and matrix [32].

Table 2. Thermal properties of the composites.

\begin{tabular}{lllll}
\hline Samples & $\begin{array}{l}\text { Crystallinity } \\
(\%)\end{array}$ & $\begin{array}{l}\mathrm{T}_{\text {onset }} \\
\left({ }^{\circ} \mathrm{C}\right)\end{array}$ & $\begin{array}{l}\mathrm{T}_{\max } \\
\left({ }^{\circ} \mathrm{C}\right)\end{array}$ & $\begin{array}{l}\text { Residue } \\
(\text { wt. } \%)\end{array}$ \\
\hline UP & 44 & 359 & 410 & 3.0 \\
RUPC & 53 & 313 & 416 & 4.5 \\
SUPC & 58 & 358 & 417 & 5.8 \\
DUPC & 50 & 313 & 417 & 6.0 \\
\hline
\end{tabular}
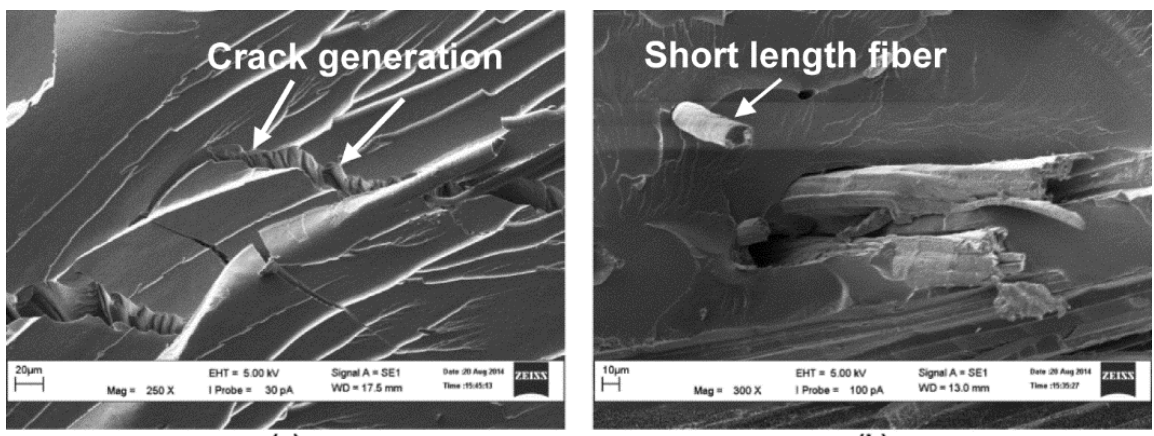

(a)

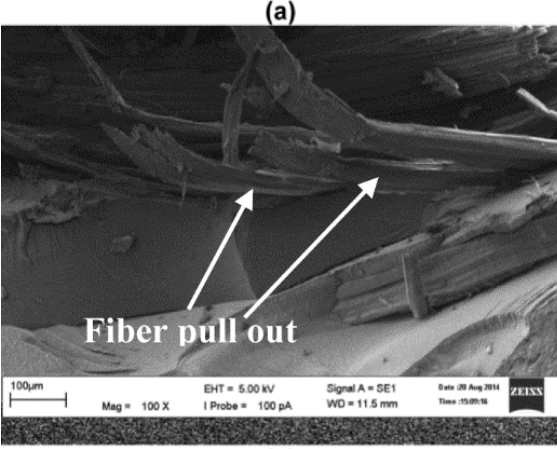

(c)

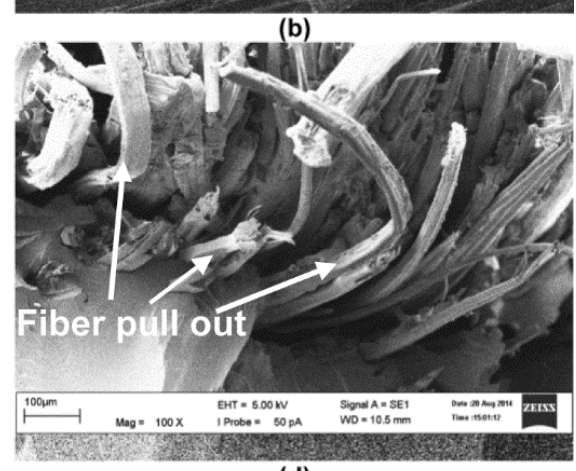

(d)

Figure 6. SEM images of the fractured samples of the composites: (a) UP, (b) RUPC, (c) SUPC and (d) DUPC.

\section{Thermal Properties}

The weight versus temperature, and the derivative weight versus temperature plots from thermogravimetric analysis are illustrated in Figures 7 and 8, respectively. Table 2 shows the onset degradation temperature $\left(\mathrm{T}_{\mathrm{onset}}\right)$ of different samples. The onset of the degradation was started for PU at temperature of $359^{\circ} \mathrm{C}$, which was decreased due to randomly oriented short kenaf fibre incorporation and started at temperature of $313^{\circ} \mathrm{C}$. This is probably due to the low temperature sustainability of natural bio-based fibres [33]. On the other hand, the single layered mat reinforced composite showed an onset degradation temperature of $358^{\circ} \mathrm{C}$, which was close to pure UP, which was due to better reinforcing arrangement of the structured fibre mat and UP [33]. DUPC showed lower onset stability by showing degradation at $318^{\circ} \mathrm{C}$, which is because of fibres agglomeration, as confirmed by the SEM image. From Figure 8, the $\mathrm{T}_{\max }$ of PU, RUPC, SUPC and DUPC was found to be $410,416,417$ and $417{ }^{\circ} \mathrm{C}$, respectively (Table 2). The 
residue of the samples was found to be 3.0, 4.5, 5.8 and 6.0\%, respectively (Figure 7). Due to the presence of natural fibres inside the polyester based composites, the degradation profile can be explained in three steps. The removal of moisture was observed after $100^{\circ} \mathrm{C}$, which corresponds to about 1.0 to $2.0 \%$ weight loss. Further low molecular weight compounds were found to be degraded after $250^{\circ} \mathrm{C}$ and the estimated weight loss was confirmed as nearly $20 \%$. Finally, the main degradation occurred at around $350^{\circ} \mathrm{C}$ due to polymer chain break down, and completed by $450^{\circ} \mathrm{C}$ with residues stated earlier.

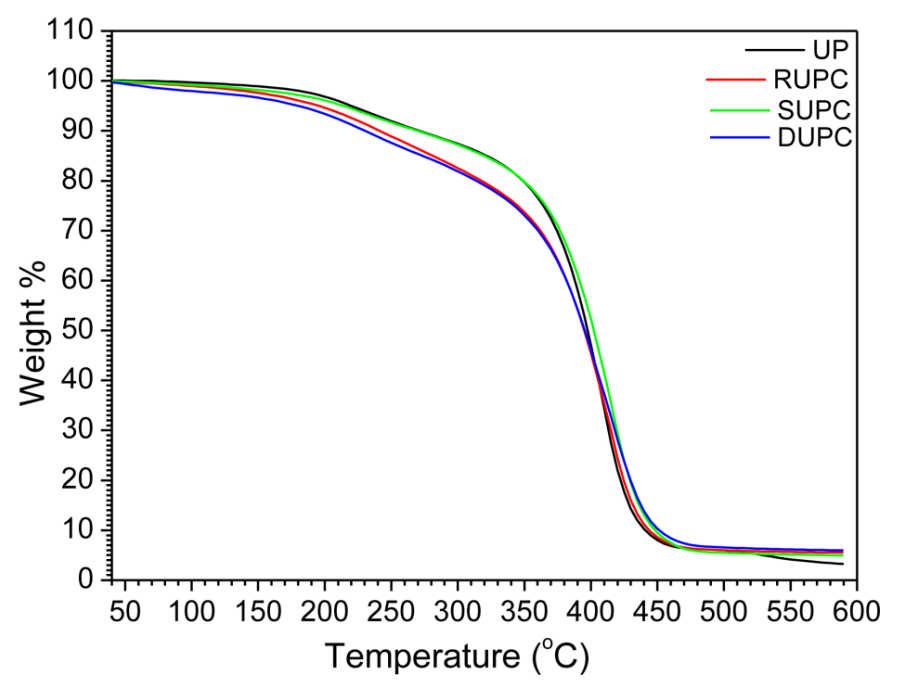

Figure 7. TGA analysis of different composites.

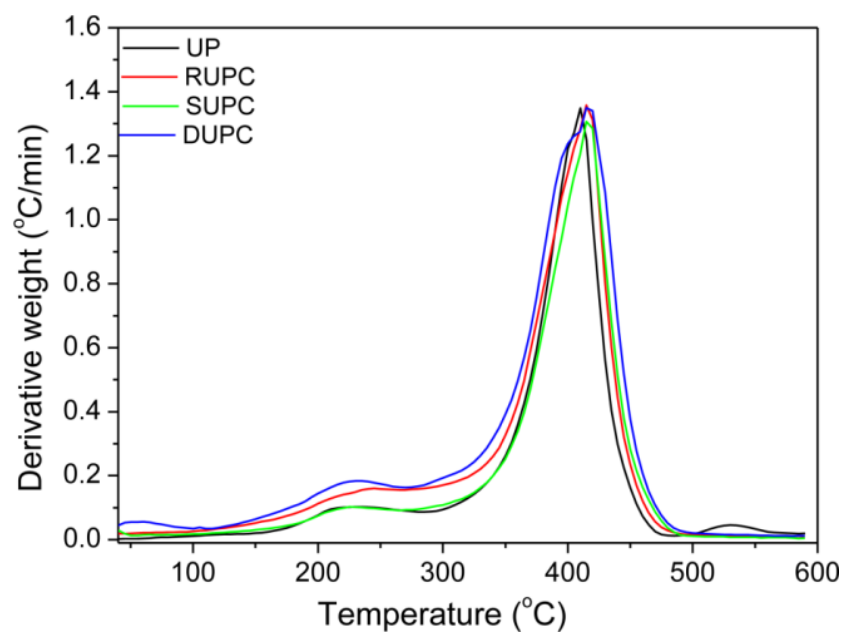

Figure 8. Derivative weight vs temperature curves of different composites.

\section{CONCLUSIONS}

The arrangement of reinforcement of long kenaf fibre was assessed for the preparation of unsaturated polyester resin based bio-composites. It was found that randomly oriented fibres based composite (RUPC) showed better mechanical strength than pure UP. On the other hand, single layer based composite (SUPC) showed improved tensile, flexural and impact properties compared to RUPC. While considering the properties of DUPC, it was found that the impact strength was lower. The surface morphology of RUPC and SUPC 
was also found to be better than DUPC as confirmed by short length fibres. The crystallinity was found to be improved with single layered kenaf mat incorporation, whereas double layered mat was found to have discouraging outcome. Finally, the thermal stability of the composites was found to be close to each other and the degradation completed before reaching $450^{\circ} \mathrm{C}$.

\section{ACKNOWLEDGEMENTS}

Authors acknowledge the ministry of higher education for the financial support of this research work through the research grant PRGS 120802.

\section{REFERENCES}

[1] Pickering KL, Efendy MA, Le TM. A review of recent developments in natural fibre composites and their mechanical performance. Composites Part A: Applied Science and Manufacturing. 2016;83:98-112.

[2] Saheb DN, Jog J. Natural fiber polymer composites: a review. Advances in polymer technology. 1999;18:351-63.

[3] Ashik K, Sharma RS. A review on mechanical properties of natural fiber reinforced hybrid polymer composites. Journal of Minerals and Materials Characterization and Engineering. 2015;3:420-6.

[4] Biagiotti J, Fiori S, Torre L, López-Manchado M, Kenny JM. Mechanical properties of polypropylene matrix composites reinforced with natural fibers: a statistical approach. Polymer composites. 2004;25:26-36.

[5] M. Haameem JA, Abdul Majid MS, Afendi M, Haslan M, Fahmi I. Alkaline treatment and thermal properties of Napier grass fibres. International Journal of Automotive and Mechanical Engineering. 2016;13:3238-47.

[6] Fahmi I, Abdul Majid MS, Afendi M, Helmi EA, M. Haameem JA. Low-velocity impact responses of Napier fibre/polyester composites. International Journal of Automotive and Mechanical Engineering. 2016;13:3226-37.

[7] Taufik RS, Adibah M NF, Muhamad MR, Hasib H. Feasibility study of natural fiber composite material for engineering application. Journal of Mechanical Engineering and Sciences. 2014;6:940-8.

[8] Azrin Hani AR, Shaari MF, Mohd Radzuan NS, Hashim MS, Ahmad R, Mariatti M. Analysis of woven natural fiber fabrics prepared using self-designed handloom. International Journal of Automotive and Mechanical Engineering. 2013;8:1197-206.

[9] Islam M, Beg M, Gupta A, Mina M. Optimal performances of ultrasound treated kenaf fiber reinforced recycled polypropylene composites as demonstrated by response surface method. Journal of Applied Polymer Science. 2013;128:284756.

[10] Omrani E, Menezes PL, Rohatgi PK. State of the art on tribological behavior of polymer matrix composites reinforced with natural fibers in the green materials world. Engineering Science and Technology, an International Journal. 2016;19:717-36.

[11] Ahsan Q, Mohamad N, Soh TC.Effects of accelerators on the cure characteristics and mechanical properties of natural rubber compounds. International Journal of Automotive and Mechanical Engineering. 2015; 12:2954-66. 
[12] Islam MR, Beg MDH, Gupta A. Characterization of alkali-treated Kenaf fibrereinforced recycled polypropylene composites. Journal of Thermoplastic Composite Materials. 2014;27:909-32.

[13] Islam M, Beg $\mathbf{M}$, Mina $M$. Fibre surface modifications through different treatments with the help of design expert software for natural fibre-based biocomposites. Journal of Composite Materials. 2013;48:1887-99.

[14] Ismail AE, Aziz MCA. Tensile strength of woven yarn kenaf fiber reinforced polyester composites. Journal of Mechanical Engineering and Sciences 2015;9:1695-704.

[15] Islam MR, Beg MD, Gupta A. Characterization of laccase-treated kenaf fibre reinforced recycled polypropylene composites. BioResources. 2013;8:3753-62.

[16] Kasim A, Selamat M, Daud M, Yaakob M, Putra A, Sivakumar D. Mechanical properties of polypropylene composites reinforced with alkaline treated pineapple leaf fibre from Josapine cultivar. International Journal of Automotive and Mechanical Engineering. 2016;13:3517-167.

[17] Mei GS, Yuvaraj AR, Kabeb SMb, Yusoff MM, Chigrinov VG, Hegde G. Biocompatible polymer embedded in light-sensitive materials: investigation of structural properties. International Journal of Automotive and Mechanical Engineering. 2014;10:2025-33.

[18] Abu Bakar MH, Raja Abdullah RI, Md. Ali MA, Kasim MS, Sulaiman MA, Ahmad SSN, et al. Surface Integrity of LM6 Aluminum Metal matrix composite when machined with high speed steel and uncoated carbide cutting tools. Journal of Mechanical Engineering and Sciences. 2014;6:854-62.

[19] Aeyzarq Muhammad Hadzreel MR, Siti Rabiatull Aisha I. Effect of Reinforcement Alignment on the Properties of Polymer Matrix Composite. Journal of Mechanical Engineering and Sciences. 2013;4:548-54.

[20] Alavudeen A, Rajini N, Karthikeyan S, Thiruchitrambalam M, Venkateshwaren N. Mechanical properties of banana/kenaf fiber-reinforced hybrid polyester composites: Effect of woven fabric and random orientation. Materials \& Design. 2015;66:246-57.

[21] Salleh FM, Hassan A, Yahya R, Lafia-Araga RA, Azzahari AD, Nazir MNZM. Improvement in the mechanical performance and interfacial behavior of kenaf fiber reinforced high density polyethylene composites by the addition of maleic anhydride grafted high density polyethylene. Polymer Research. 2014;21:439-42.

[22] Ismail AE, Che Abdul Aziz MA. Tensile strength of woven yarn kenaf fiber reinforced polyester composites. Journal of Mechanical Engineering and Sciences. 2015;9:1695-704.

[23] Umar AH, Zainudin ES, Sapuan SM. Effect of accelerated weathering on tensile properties of kenaf reinforced high-density polyethylene composites. Journal of Mechanical Engineering and Sciences. 2012;2:198-205.

[24] Fairuz A, Sapuan S, Zainudin E, Jaafar C. Effect of filler loading on mechanical properties of pultruded kenaf fibre reinforced vinyl ester composites. Journal of Mechanical Engineering and Sciences. 2016;10:1931-42.

[25] Fahmi I, Majid MA, Afendi M, Helmi E, Haameem J. Low-velocity impact responses of Napier fibre/polyester composites International Journal of Automotive and Mechanical Engineering. 2016;13:3226-37.

[26] Shah DU, Schubel PJ, Licence P, Clifford MJ. Determining the minimum, critical and maximum fibre content for twisted yarn reinforced plant fibre composites. Composites Science and Technology. 2012;72:1909-17. 
[27] Sultana Mir S, Hasan M, Hasan S, Hossain M, Nafsin N. Effect of chemical treatment on the properties of coir fiber reinforced polypropylene and polyethylene composites. Polymer Composites. 2015.

[28] Samariha A, Bastani A, Nemati M, Kiaei M, Nosrati H, Farsi M. Investigation of the mechanical properties of bagasse flour/polypropylene composites. Mechanics of Composite Materials. 2013;49:447-54.

[29] Mohanty S, Verma SK, Nayak SK. Dynamic mechanical and thermal properties of MAPE treated jute/HDPE composites. Composites Science and Technology. 2006;66:538-47.

[30] Rong MZ, Zhang MQ, Liu Y, Yang GC, Zeng HM. The effect of fiber treatment on the mechanical properties of unidirectional sisal-reinforced epoxy composites. Composites Science and Technology. 2001;61:1437-47.

[31] Rahman MM, Afrin S, Haque P. Characterization of crystalline cellulose of jute reinforced poly (vinyl alcohol)(PVA) biocomposite film for potential biomedical applications. Progress in Biomaterials. 2014;3:1-9.

[32] Mokaloba N, Batane R. The effects of mercerization and acetylation treatments on the properties of sisal fiber and its interfacial adhesion characteristics on polypropylene. International Journal of Engineering, Science and Technology. 2014;6:83-97.

[33] Saravana B, Mohan K. Thermal properties of maize fiber reinforced unsaturated polyester resin composites. Proceedings of the World Congress of Engineering. London, UK; 2013. 